\title{
VARIASI MAKSUD KATA EMOTIF "WELA" DALAM BAHASA JAWA: PERSPEKTIF SOSIOPRAGMATIK
}

Meaning Variations of Javanese Emotive Word "wela":

A Sociopragmatics Perspective

\author{
R. Kunjana Rahardi \\ Universitas Sanata Dharma Yogyakarta \\ kunjana.rahardi@gmail.com
}

Naskah Diterima Tanggal 3 Maret 2020_Direvisi Akhir Tanggal 13 Oktober 2020_Disetujui Tanggal 15 November 2020 doi: https://doi.org/10.26499/rnh.v9i2.2937

\begin{abstract}
Abstrak
Penelitian ini bertujuan mendeskripsikan variasi manifestasi maksud kata emotif "wela" dalam bahasa Jawa. Data penelitian berupa cuplikan-cupkikan tuturan yang di dalamnya terkandung variasi maksud kata emotif "wela". Sumber data substantifnya adalah tuturan keseharian warga masyarakat perdesaan yang di dalamnya terdapat manifestasi variasi maksud kata emotif "wela". Data dikumpulkan dengan metode simak dan cakap. Metode simak dilakukan dengan teknik rekam dan catat. Metode cakap dilaksanakan dengan teknik cakap semuka dan cakap tansemuka. Langkah selanjutnya adalah identifikasi data, klasifikasi data, dan tipifikasi data. Data yang telah ditipe-tipekan lalu dikenai metode dan teknik analisis data, tetapi sebelumnya ditriangulasikan terlebih dahulu kepada pakar. Analisis data dilakukan dengan metode analisis padan ekstralingual. Melalui penelitian ini telah ditemukan enam maksud kata emotif "wela"dalam bahasa Jawa, yakni maksud: (1) menunjukkan maksud keterkejutan, (2) menunjukkan maksud pembelaan, (3) menunjukkan maksud mengingatkan, (4) menunjukkan maksud keheranan, (5) menenunjukkan maksud kelegaan untuk bersyukur, dan (6) menunjukkan maksud kekecewaan.
\end{abstract}

Kata-kata Kunci: Kata-kata emotif, makna pragmatik, bahasa Jawa, sosiopragmatik

\begin{abstract}
This study aims to describe manifestation of the variations of meanings of the emotive word "wela" in Javanese language. The research data were in the form of snippets of utterances which contain variations of meaning of the Javanese emotive word "wela". The source of the substantive data was the daily speech of villagers in which there were manifestations of variations in the meaning of the emotive word "wela". The data were collected using the observation and interview method. The observation method was done by using the recording and notetaking technique. The interview method was carried out with the face-to-face interview and the indepth interviewing techniques. The next step is the data identification, data classification, and data typification. Data that had been typified were then subjected to data analysis methods and techniques, but previously triangulated to the experts. Data analysis was performed using extralingual equivalent analysis method. Through this research, six meanings of the emotive word "wela" have been found in Javanese language, namely: (1) showing the intention of surprise, (2) showing the intention of defense, (3) showing the intention of reminding, (4) showing the intention of surprise, (5) shows the intention of relief to give thanks, and (6) shows the intention of disappointment.
\end{abstract}

Keywords: Emotivel words, pragmatics meaning, Javanese language, sociopragmatics

How to Cite: Rahardi, R. Kunjana. (2020). Variasi Maksud Kata Emotif “Wela” dalam Bahasa Jawa: Perspektif Sosiopragmatik. Ranah: Jurnal Kajian Bahasa. 9(2). 246-259. doi: https://doi.org/10.26499/rnh.v9i2.2937 


\section{PENDAHULUAN}

Penelitian tentang kata-kata emotif atau kata afektif dalam perspektif linguistik sudah tidak banyak lagi dilakukan oleh peneliti (R. K. Rahardi, 2010). Para peneliti sudah cukup lama berpaling kepada kajian-kajian kebahasaan dalam perspektif fungsional, bukan lagi perspektif formalistik seperti sebelumnya. Mereka beralih ke dalam perspektif fungsional tidak tanpa alasan, tetapi benar-benar dilandasi oleh kesadaran bahwa belajar bahasa sesungguhnya adalah belajar berkomunikasi (Norrick, 2009). Pandangan tersebut tentu tidak sepenuhnya benar, tetapi kini telah telanjur menjadi semacam mainstream dalam pengkajian bahasa. Demikian pula penelitian-penelitian dapam perspektif interdisipliner, sekarang ini mulai beralih pada perspektif yang bersifat multidisipliner, atau bahkan bersifat transdisipliner. Persoalan-persoalan luar kebahasaan yang bertali-temali dengan bahasa yang semakin komplekslah yang menjadi salah satu pemicu hadirnya pendekatan studi yang demikian ini.

Berbicara tentang perspektif sosiolinguistik dalam mengkaji fenomena bahasa emotif memang tidak dapat menjawab persoalan maksud dalam komunikasi (Caffi \& Janney, 1994). Itulah salah satu alasan mendasar mengapa penelitian bahasa dalam perspektif sosiolinguistik seolah-olah juga semakin stagnan dalam perkembangannya. Pokok perbincangan dalam sosiolingustik adalah pada variasi-variasi bahasa, bukan pertama-tama kepada fungsi bahasa, apalagi maksud bahasa (Holmes \& Marra, 2002). Kendati demikian, peralihan perbincangan ke dalam variasi-variasi bahasa itu telah berjasa bagi perkembangan paradigma studi bahasa, yakni dari semula yang bersifat formalistik menuju keadaan sekarang yang menjadi bersifat fungsionalistik.

Sosiolinguistiklah yang sesungguhnya pertama-tama dapat dianggap sebagai pendobraknya. Hal demikian sejalan pula dengan yang disampaikan oleh Eiunar Haugen (1972) sebagai penginisiasi studi lingkungan atau ekologi bahasa dalam pengertian metaforis, yang selanjutnya memicu kelahiran disiplin ekolinguistik selain juga sosiolinguistik sebagaimana yang diteruskan Wardhough dan teman-temannya (Peace \& Mühlhäusler, 2006). Jadi perkembangan ilmu interdisipliner sosiolinguistik memang tidak terlampau menggembirakan sebagaimana yang terjadi pada bidang-bidang bahasa dengan berbagai talitemali transdisipliner dan multidisiplinernya.

Dengan demikian, studi kata-kata emotif dari perspektif sosiolinguistik juga tidak banyak dilakukan oleh para peneliti bahasa karena studi tersebut hanya akan berhenti pada manifestasi varian-varian bentuk dari bentuk kebahasan itu. Pendekatan sosiopragmatik diambil dalam kajian kata emotif "wela” dalam bahasa Jawa di sini karena dengan perspektif 
itu akan terjawab persoalan maksud dari pemerantian kata emotif "wela" itu dalam pertuturan natural (Leech, 2014). Dikatakan demikian karena dalam sosiopragmatik itu dimensi maksud menjadi salah satu perhatian pokok kajian mengingat bahwa sosiopragmatik memiliki pijakan kaki pada bidang pragmatik yang hakikatnya mengkaji maksud itu.

Selanjutnya, rumusan masalah penelitian ini adalah bagaimana manifestasi maksud kata emotif "wela" dalam bahasa Jawa dilihat dari kacamata sosiopragmatik. Sejalan dengan rumusan masalah itu maka tujuan penelitian ini adalah untuk mendeskrupsikan manifestasi maksud kata emotif "wela” dalam perspektif sosiopragmatik itu.

\section{LANDASAN TEORI}

Pragmatik merupakan cabang terbaru dari linguistik maka perhatian sosiopragmatik bukan saja kepada dimensi pragmatik, melainkan juga pasti bertali-temali dengan linguistik. Hal penting yang juga harus disampaikan di sini adalah pijakan kaki sosiopragmatik itu bukan saja pada ilmu pragmatik, melainkan juga pada aspek-aspek sosial atau kemasyarakatan (Fu, 2004). Dengan demikian, sosiopragmatik itu bertumpu pada tiga hal, yakni pada sosiologi, linguistik, dan pragmatik. Jadi memang cukup beralasan kalau dikatakan bahwa sosiopragmatik sesungguhnya merupakan bidang multidisipliner, bukan lagi bidang interdisipliner seperti halnya sosiolinguistik (Holmes \& King, 2017).

Berkaitan dengan sosiopragmatik ini, Leech (1984) sebagai pencetus perdana nama sosiopragamtik telah memberikan imbangan bidang lain yang lebih berpija pada linguistik, yakni pragmalinguistik. Berbeda dengan sosiopragmatik yang bertumpu pada aspek-aspek sosial dan aspek-aspek pragmatik, pragmalinguistik lebih bertumpu pada aspek-aspek linguistik (Leech, 2014). Dalam buku terbarunya, Rahardi (2020) juga menyebut bahwa pragmatik sebagai bidang ilmu yang dekat dengan semantik karena pragmatik dan semantik sesungguhnya memiliki kesamaan dalam hal perhatian pada kajian makna. Hanya bedanya semantik mengkaji makna dalam perspektif linguistik atau yang bersifat sistemik, sedangkan pragmatik lebih berfokus pada bidang yang bersifat luar kebahasaan atau ekstralinguistik (Helmon \& Rahardi, 2020). Dengan demikian, dapat ditegaskan bahwa pragmalinguistik dapat pula disebut sebagai pragmatik yang bersifat sistemik atau yang sering pula disebut semantiko-pragmatik.

Selanjutnya sebagai dasar teori untuk memayungi penelitian tentang kata emotif "wela" dalam bahasa Jawa ini, pragmatik yang digunakan sebagai perspektif adalah pragmatik dalam pengertian kultur-spesifik. Jadi bukan pragmatik dalam pengertian umum (general 
pragmatics) yang berlaku universal, yang didasarkan pada kaidah-kaidah pragmatik dunia Barat, melainkan pragmatik yang digali dari kearifan budaya yang terdapat pada masyarakat dan suku tertentu di Indonesia (Rahardi, R. Kunjana., Setyaningsih, 2019). Dalam kaitan dengan kata emotif "wela” itu, kearifan budaya yang dimaksud adalah kearifan budaya masyarakat Jawa, seperti yang terdapat dalam bentuk kebahasaan berikut, "Wela, ra sido tenan ini!", yang artinya dalam bahasa Indonesia adalah 'Wela, tidak jadi sungguh-sungguh ini!' Demikian juga bentuk "wela” pada tuturan "Wis bola-bali dijelaske, wela” yang dalam bahasa Indonesia berarti, 'sudah berkali-kali dijelaskan, wela'. Secara pragmatik, penempatan kata emotif "wela” yang tidak sama pada kedua cuplikan tuturan itu melahirkan maksud yang tidak sama pula.

Secara linguistik, perbedaan penempatan entitas kebahasan yang demikian itu tentu tidak akan banyak memberi arti apa-apa. Adapun secara sosiolinguistik, perbedaan demikian itu akan dipandang semagai semata-mata variasi pemakaian bahasa saja (Orsini-Jones \& Lee, 2018). Jadi, itulah salah satu alasan mendasar mengapa "wela" dalam bahasa Jawa ini dikaji dengan perspektif sosiopragmatik. Kajian pragmatik dan sosiopragmatik tentu tidak lepas dari perbincangan ihwal konteks, baik konteks yang sifatnya sosial, sosietal, kultural, maupun situasional.

Ihwal identitas dari setiap jenis konteks itu sudah dijelaskan dalam Rahardi (2000), dan secara singkat dapat ditegaskan kembali di sini. Konteks sosial menunjuk pada aspek-aspek kemasyarakatan yang berdimensi mendatar atau horizontal. Konteks sosietal menunjuk pada aspek-aspek kemasyarakatan juga, tetapi dimensinya vertikal. Konteks kultural bertali-temali dengan dimensi-dimensi budaya dan kearifan nilai-nilainya pada masyarakat dan suku bangsa tertentu. Adapun konteks situasi menunjuk pada suasana terjadinya sebuah peristiwa kebahasaan (R. K. Rahardi, 2019). Payung referensi (frame of reference) penelitian ini adalah teori-teori yang semuanya telah disampaikan di bagian depan itu. Demikian pula, alat analisis (tools of analysis) penelitian ini tidak lepas dari teori-teori yang dipaparkan di depan itu.

\section{METODE PENELITIAN}

Persoalan metode adalah persoalan yang sangat krusial dalam kajian ilmiah kebahasaan. Metode itu utamanya bertali-temali dengan persoalan alat dan persoalan cara (R. K. Rahardi, 2009a). Akan tetapi, ihwal cara dan alat itu tidak lepas pula dengan konsep kedataan lingualnya. Dalam kaitan dengan penelitian kata emotif "wela” dalam bahasa Jawa ini maka yang dimaksud dengan konsep kedataan ini adalah kedataan lingual bahasa Jawa. Data 
penelitian ini adalah cuplikan-cuplikan tuturan yang di dalamnya terkandung variasi maksud kata emotif "wela". Maka dari itu, sumber data substantifnya adalah tuturan-tuturan dalam keseharian bertutur yang di dalamnya terdapat manifestasi variasi maksud kata emotif "wela" dalam bahasa Jawa keseharian yang dituturkan oleh warga masyarakat (Sudaryanto, 2016); (Mahsun, 2005).

Sebagai penelitian yang bersifat fenomenologis, identitas dan jumlah narasumber tidak perlu dipersoalkan dalam kajian ini. Alasannya, fenomena pemakaian dan pemaknaan secara pragmatis kata "wela" itulah yang dijadikan fokus perbincangan. Jadi bukan persoalan jumlah dan kejelasan identitas dari penuturnya. Hanya saja perlu ditegaskan di sini bahwa pilihan penulis untuk mengambil para penutur di perdesaan tertentu adalah karena di tempattempat itulah tersedia data lingual yang melimpah dan bersifat natural (Sudaryanto, 2015). Tempat asal-muasal data seperti disampaikan di depan itulah yang dimaksud dengan sumber data lokasional dalam penelitian sosiopragmatik ini.

Adapun hasil transkripsi dari tuturan-tuturan yang disampaikan secara natural oleh warga masyarakat yang di dalamnya terdapat manifestasi variasi kata emotif "wela" itulah sumber data substantifnya. Data penelitian ini dikumpulkan dengan metode simak dan metode cakap. Metode simak dilakukan secara teknis dengan teknik rekam dan teknik catat. Adapun metode cakap dalam pengumpulan data dilaksanakan secara teknis dengan teknik cakap semuka dan teknik cakap tansemuka (Sudaryanto, 2015); (Mahsun, 2005). Setelah data terkumpul dengan baik, langkah selanjutnya adalah identifikasi data, yang dilanjutkan dengan klasifikasi data dan tipifikasi data.

Langkah yang terakhir dalam tahapan pengumpulan data ini adalah langkah tipifikasi data yang menghasilkan tipe-tipe data yang siap untuk dikenakan metode dan teknik analisis data setelah sebelumnya ditriangulasikan terlebih dahulu. Triangulasi data dilakukan kepada pakar, selain itu juga triangulasi dikenakan pada teori-teori yang relevan.

Analisis data dilakukan dengan menerapkan metode analisis padan karena penelitian ini berdimensi ekstralingual. Adapun metode padan yang digunakan, sejalan dengan sifat datanya, adalah metode padan ekstralingual dengan teknik hubung banding (Mahsun, 2005). Hasil analisis data disajikan dengan secara informal seperti yang lazim dilakukan dalam pelaporan penelitian-penelitian kebahasaan secara deskriptif-kualitatif. 


\section{PEMBAHASAN}

Peneliti telah melakukan percermatan terhadap data yang berhasil dikumpulkan, diklasifikasi, dan ditipifikasi dari pertuturan natural warga masyarakat di perdesaan tertentu. Terdapat enam maksud kata emotif "wela" dalam bahasa Jawa dari data yang dapat dikumpulkan oleh peneliti. Keenam maksud itu secara berturut-turut disampaikan sebagai berikut: (1) maksud menunjukkan maksud keterkejutan atau kekagetan, (2) maksud menunjukkan pembelaan, (3) maksud menunjukkan pengingatan, (4) maksud menunjukkan keheranan, (5) maksud menununjukkan kelegaan untuk bersyukur, dan (6) maksud menunjukkan kekecewaan.

Pada tabel 1 berikut ini, wujud-wujuyd data yang menunjukkan maksud-maksud tersebut disajikan dengan konteks indeksalnya.

Tabel 1.

Manifestasi Maksud Kata Emotif "wela”

\begin{tabular}{|c|c|c|c|}
\hline $\begin{array}{l}\text { Kode } \\
\text { Data }\end{array}$ & Data tuturan dan translasinya & Konteks indeksal tuturannya & $\begin{array}{l}\text { Maksud } \\
\text { tuturan }\end{array}$ \\
\hline DKWBJ1 & $\begin{array}{l}\text { A: Wela, anakku mau mlayu neng } \\
\text { endi? Kok mak blas njur ra ketok } \\
\text { ya. } \\
\text { B: Kae mlayu neng ngisor wit. } \\
\text { Wong pengin sing edum kok. } \\
\text { (A: Wela, anakku tadi lari ke mana } \\
\text { ya? Kok, terus pergi tidak terlihat } \\
\text { lagi. } \\
\text { B: Itu lari ke bawah pohon. Orang } \\
\text { mau mencari tempat yang rindang, } \\
\text { kok.) }\end{array}$ & $\begin{array}{l}\text { Tututan ini terjadi di antara para ibu } \\
\text { rumah tangga yang sedang mengasuh } \\
\text { anak-anaknya di sore hari di sebuah } \\
\text { perdesaan. Biasanya di sore hari, ibu- } \\
\text { ibu rumah tangga mengasuh anak- } \\
\text { anak kecil mereka sambil menyuapi } \\
\text { makan sore di tanah yang relatif } \\
\text { lapang dan banyak pepohonan. } \\
\text { Suasana pertuturan sangat santai dan } \\
\text { biasanya para ibu rumah tangga itu } \\
\text { asyik merumpi hingga tidak } \\
\text { memperhatikan ke mana anak kecil } \\
\text { yang diasuhnya berlari. }\end{array}$ & $\begin{array}{l}\text { Menunjukan } \\
\text { maksud } \\
\text { keterkejutan }\end{array}$ \\
\hline DKWBJ2 & $\begin{array}{l}\text { A: Wis dijelaske bola-bali kok yo ra } \\
\text { paham tho! Mbok yo digatekke sing } \\
\text { temenan! } \\
\text { B: Wela, aku ki yo wis sinau lan } \\
\text { nggatekke lho. Pancen angel tenan } \\
\text { kok. } \\
\text { A: Wela...wela...wela. Nek nganti } \\
\text { ra lulus awas kowe. Ra tak kei } \\
\text { dhuwit maneh sesok. } \\
\text { (A: sudah dijelaskan berkali-kali } \\
\text { kok ya tidak paham, tho! Mohon } \\
\text { diperhatikan yang serius. } \\
\text { B: Wela, saya itu juga sudah } \\
\text { belajar dan memberhatikan, lo. } \\
\text { Memang sulit sekali,kok. } \\
\text { A: Wela...wela...wela. Kalau } \\
\text { sampai tidak lulus awas kamu. } \\
\text { Tidak akan saya kasih uang lagi } \\
\text { besok.) }\end{array}$ & $\begin{array}{l}\text { Perbincangan terjadi antara seorang } \\
\text { ibu dengan anaknya yang masih } \\
\text { bersekolah di sekolah dasar di } \\
\text { desanya. Di masa yang sangat sulit } \\
\text { sebagai dampak pandemi Covid-19 } \\
\text { ini, kinerja anak-anak dalam belajar } \\
\text { cenderung rendah. Tingkat } \\
\text { pemahaman anak-anak sekolah juga } \\
\text { tidak bagus karena berbagai faktor. } \\
\text { Sang ibu mengancam dan memarahi } \\
\text { anaknya karena belajarnya kurang } \\
\text { baik. Kendati begitu, anak tersebut } \\
\text { mengelak bahwa dirinya tidak } \\
\text { belajar. "Persoalan dalam belajar itu } \\
\text { memang sulit" kilahnya. }\end{array}$ & $\begin{array}{l}\text { Menunjukkan } \\
\text { maksud } \\
\text { pembelaan }\end{array}$ \\
\hline
\end{tabular}




\begin{tabular}{|c|c|c|c|}
\hline $\begin{array}{l}\text { Kode } \\
\text { Data }\end{array}$ & Data tuturan dan translasinya & Konteks indeksal tuturannya & $\begin{array}{l}\text { Maksud } \\
\text { tuturan }\end{array}$ \\
\hline DKWBJ3 & $\begin{array}{l}\text { A: Nek wis wareg yo wis, wela. } \\
\text { Mengko nek wetenge mlembung } \\
\text { piye? } \\
\text { B: Aku rung wareg, Mbok. Enak } \\
\text { tenan je iwake. } \\
\text { A: Yo wis kono entekno. Bocah kok } \\
\text { senenge madhang! } \\
\text { (A: Kalau sudah kenyang ya sudah, } \\
\text { wela. Nanti kalau perutmu } \\
\text { mengembung bagaimana? } \\
\text { B: Aku belum kenyang, Bu. Enak } \\
\text { sekali tuh ikannya. } \\
\text { A: Ya sudah silakan dihabiskan. } \\
\text { Anak kok senangnya makan!) }\end{array}$ & $\begin{array}{l}\text { Perbincangan ini terjadi dalam } \\
\text { sebuah rumah tangga miskin di } \\
\text { sebuah desa. Seorang anak sedang } \\
\text { makan banyak-banyak karena } \\
\text { kelaparan dan merasakan bahwa lauk } \\
\text { ikannya sangat enak sehingga } \\
\text { kegiatan makan itu tidak segera } \\
\text { selesai. Kemudian, sang ibu } \\
\text { membiarkan anak tersebut untuk } \\
\text { menghabiskan makanan dan } \\
\text { laukknya sambil bergumam. } \\
\text { Pertuturan ini sangat sering terjadi } \\
\text { dalam sebuah keluarga yang } \\
\text { sederhana di sebuah perdesaan. }\end{array}$ & $\begin{array}{l}\text { Menunjukkan } \\
\text { maksud } \\
\text { mengingatkan }\end{array}$ \\
\hline DKWBJ4 & $\begin{array}{l}\text { A: Wela, kojur tenan iki! Teles } \\
\text { kabeh iki kasure, Mbok. } \\
\text { B: Lha piye to, Le. Ngompol ya } \\
\text { adimu? Wah jan, bocah ra nggenah } \\
\text { tenan kok. } \\
\text { A: Yo ben to, Mbok. Wong cah cilik } \\
\text { ngompol kok dinesoni. } \\
\text { (A: Wela, celaka bener ini! Basah } \\
\text { semua ini kasurnya, Bu. } \\
\text { B: Lha piye to, Nak. Ngompol ya } \\
\text { adikmu? Wah sialan, anak tidak } \\
\text { tahu diri bener, kok. } \\
\text { A: Ya sudah biar to, Bu. Orang } \\
\text { anak kecil ngompol kok dimarahi.) }\end{array}$ & $\begin{array}{l}\text { Perbincangan ini terjadi antara } \\
\text { seorang ibu dengan anaknya yang } \\
\text { sudah cukup besar. Anak tersebut } \\
\text { memiliki adik yang masih kecil dan } \\
\text { biasa tidur sambil mengompol di } \\
\text { tempat tidur. Sang ibu marah, tetapi } \\
\text { diturunkan emosi tingginya oleh sang } \\
\text { anak yang sudah relatif lebih besar } \\
\text { itu. Pertuturan yang terkesan tidak } \\
\text { bernuansa harmonis dan cenderung } \\
\text { kasar demikian ini banyak terjadi di } \\
\text { desa-desa. Latar belakang pendidikan } \\
\text { orang tua biasanya menjadi salah satu } \\
\text { penentu dari hadirnya pertuturan } \\
\text { yang tidak bagus demikian ini. }\end{array}$ & $\begin{array}{l}\text { Menunjukkan } \\
\text { maksud } \\
\text { keheranan }\end{array}$ \\
\hline DKWBJ5 & $\begin{array}{l}\text { A: Wela, sokur tenan wis wiwit } \\
\text { grimis. Bakal bisa labuh iki. } \\
\text { B: Iyo yo, Kang. Nggolek banyu kok } \\
\text { angele ra jamak. } \\
\text { A: Lha yo mongso ketiga yo ngene } \\
\text { iki. Nek kesongo yo. } \\
\text { (A: Wela, syukur sekali sudah } \\
\text { mulai hujan gerimis. Bakal bisa } \\
\text { menggarap sawah ini. } \\
\text { B: Iya ya, Mas. Mencari air kok } \\
\text { sulit sekali. } \\
\text { A: Lha ya musim kemarau ya } \\
\text { begini ini. Kalau musim hujan } \\
\text { (kesembilan) ya.) }\end{array}$ & $\begin{array}{l}\text { Pertuturan ini terjadi antarpetani di } \\
\text { persawahan. Musim hujan yang tidak } \\
\text { segera datang sangat menyusahkan } \\
\text { para petani karena tidak dapat } \\
\text { mengolah sawahnya dengan baik. } \\
\text { Pada saat itu, gerimis mulai turun, } \\
\text { dan bersyukurlah para petani karena } \\
\text { segera akan bisa bercocok tanam } \\
\text { kembali. Irigasi yang tidak lancar } \\
\text { bahkan mati tentu saja sangat } \\
\text { menyulitkan petani. }\end{array}$ & $\begin{array}{l}\text { Menunjukkan } \\
\text { maksud } \\
\text { kelegaan untuk } \\
\text { bersyukur }\end{array}$ \\
\hline DKWBJ6 & $\begin{array}{l}\text { A: Wela piye iki? Wis kebanjur } \\
\text { ditanduri je malah ra udan-udan. } \\
\text { Yo ra urip tandure. } \\
\text { B: Iyo yo. Ning yo sapa ngerti } \\
\text { ndang udan maneh. Sesuk rak terus } \\
\text { ledhung-ledhung godhonge! } \\
\text { A: Lha nek ora udan-udan ya } \\
\text { nglowos. Wong tani jan ra iso apa- } \\
\text { apa tenan. } \\
\text { (A: Wela bagaimana ini? Sudah } \\
\text { teranjur ditanami malah tidak } \\
\text { hujan-hujan. Ya tidak } \\
\text { hidup tanamannya. }\end{array}$ & $\begin{array}{l}\text { Pertuturan ini terjadi antarpara ibu di } \\
\text { desa-desa yang biasanya bekerja } \\
\text { sama menanam benih padi setelah } \\
\text { sawah selesai digarap oleh para } \\
\text { bapak petani. Pada saat itu mereka } \\
\text { mengeluhkan hujan yang tidak segera } \\
\text { kunjung turun. Dengan begitu, } \\
\text { tanaman padi yang sudah ditanam } \\
\text { tidak akan bisa tumbuh dan akhirnya } \\
\text { tidak akan memiliki panenan untuk } \\
\text { meghidupi keluarga mereka. }\end{array}$ & $\begin{array}{l}\text { Menunjukkan } \\
\text { maksud } \\
\text { kekecewaan }\end{array}$ \\
\hline
\end{tabular}




\begin{tabular}{llcc}
\hline $\begin{array}{l}\text { Kode } \\
\text { Data }\end{array}$ & Data tuturan dan translasinya & Konteks indeksal tuturannya & $\begin{array}{c}\text { Maksud } \\
\text { tuturan }\end{array}$ \\
\hline & $\begin{array}{l}\text { B: Iya ya. Tapi ya siapa tahu } \\
\text { segera hujan lagi. Besok kan terus } \\
\text { hijau-hijau subur } \\
\text { daunnya!) }\end{array}$ & \\
\hline
\end{tabular}

\section{Kata Emotif “Wela” untuk Menunjukan Maksud Keterkejutan}

Di dalam DKWBJ1 berikut ini, bentuk "wela” pada tuturan "Wela, anakku mau mlayu neng endi? Kok mak blas njur ra ketok ya.", dimaksudkan untuk menunjukkan maksud keterkejutan. Ibu sang pengasuh anak kecil itu merasa benar-benar terkejut karena anak yang diasuhnya tidak ada di dekatnya ketika dia sedang asyik berbincang-bincang dengan temanteman ibu rumah tangga yang bersama-sama mengasuh anak-anak sambil menyuapi mereka. Bentuk "wela" untuk menyatakan kekagetan atau keterkejutan lazimnya hadir di posisi awal tuturan, seperti yang tampak pada contoh tuturan di atas.

Akan tetapi, penentu maksud dari bentuk "wela” bukan semata-mata karena posisinya, melainkan terlebih-lebih karena kehadirasn konteks pertuturannya. Jadi jelas sekali bahwa secara sosiopragmatik, posisi sebuah entitas kebahasaan yang sedang dimaknai dapat berpengaruh terhadap maksud (van Compernolle \& Williams, 2012). Akan tetapi, maksud itu lebih ditentukan oleh kejelasan dan jati diri konteks sosial, sosietal, kultural, dan situasinal berikut dengan elemen-elemen konteksnya (K. Rahardi, 2016). Cuplikan tuturan berikut dapat dicermati lebih lanjut untuk mengambarkan maksud keterkejutan dengan kata emotif "wela" tersebut.

DKWBJ1

A: Wela, anakku mau mlayu neng endi? Kok mak blas njur ra ketok ya.

$B$ : Kae mlayu neng ngisor wit. Wong pengin sing edum, kok.

(A: Wela, anakku tadi lari kemana? Kok, terus pergi tidak terlihat lagi.

B: Itu lari ke bawah pohon. Orang mau mencari tempat yang rindang, kok.)

Konteks Indeksal: Tututan ini terjadi di antara para ibu rumah tangga yang sedang mengasuh anak-anaknya di sore hari di sebuah perdesaan. Biasanya di sore hari, ibu-ibu rumah tangga mengasuh anak-anak kecil mereka sambil menyuapi makan sore di tanah yang relatif lapang dan banyak pepohonan. Suasana pertuturan sangat santai, dan biasanya para ibu rumah tangga itu asyik merumpi hingga tidak memeprhatikan kemana anak kecil yang diasuhnya berlari.

\section{Kata Emotif “Wela” untuk Menunjukan Maksud Pembelaan}

Berbeda dengan maksud kata emotif "wela" seperti yang terdapat pada DKWBJ1, pada data DKWBJ2 berikut ini, maksud dari kata emotif tersebut adalah untuk menunjukkan pembelaan. Bentuk "wela” pada tuturan "Wela, aku ki yo wis sinau lan nggatekke lho. Pancen angel tenan, kok." dimaksudkan untuk menunjukkan maksud membela. Jadi maksud 
membela tersebut berbeda dengan maksud keterkejutan atau keheranan. Dari sisi posisi tuturan, "wela" pada tuturan tersebut juga berada di awal tuturan. Akan tetapi, dari segi maksud, faktor penentu maksud itu adalah konteks berikut dengan elemen-elemen konteksnya (R. K. Rahardi, 2009b), "wela” pada cuplikan di atas berbeda dengan "wela” pada cuplikan tuturan yang pertama.

Dalam cuplikan tututran berikut ini, kata emotif "wela" digunakan untuk maksud menunjukkan pembelaan dari seorang anak kepada ibunya yang terus-menerus mamaksa dan mengancam dia demi keberhasilannya dalam belajar. Hal tersebut tampak pada pemakaian bentuk emotif "wela" pada tuturan berikut, "Wela...wela...wela. Nek nganti ra lulus awas kowe. Ra tak kei dhuwit maneh sesok." Cuplikan tuturan berikut dapat dicermati lebih lanjut untuk memperjelas maksud pembelaan dengan kata emotif "wela” ini.

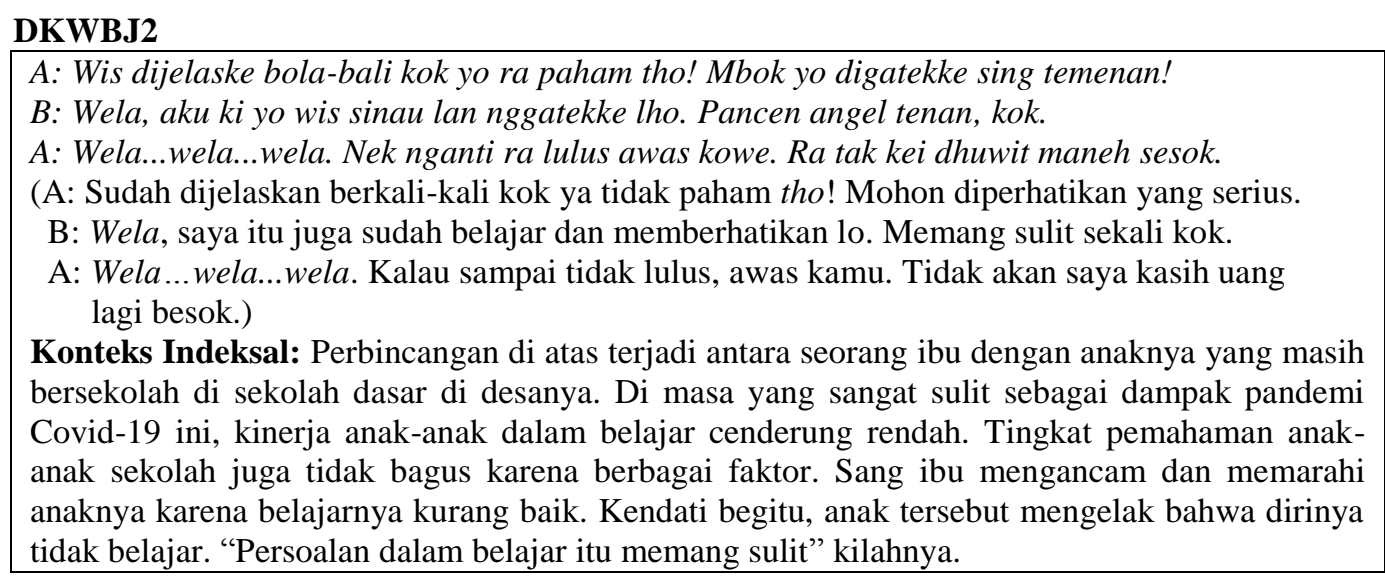

\section{Kata Emotif “Wela” untuk Menunjukkan Maksud Mengingatkan}

Kata emotif "wela" juga dapat digunakan untuk menyampaikan maksud mengingatkan. Dalam contoh tuturan pada DKWBJ3 berikut ini, Nek wis wareg yo wis, wela Mengko nek wetenge mlembung piye?' bentuk "wela" itu terdapat di tengah-tengah tuturan, bukan di awal tuturan seperti yang telah disebutkan pada dua tuturan yang disebutkan di atas tadi. Dari dimensi sosiopragmatik, bentu "wela" dengan maksud mengingatkan tersebut terjadi pada pertuturan antara seorang ibu dengan anaknya yang masih kecil dan baru senang-senangnya makan. Bilamana sedang makan sesuatu yang dia senangi, anak tersebut tidak akan cepat mengakhiri kegiatan makan tersebut sampai dikatakan oleh sang ibu, "mengko nek wetenge mlembung”.

Jadi penentu maksud "wela" pada tuturan berikut ini bukan pertama-tama pada posisinya, tetapi pada aspek-aspek elemen konteks yang hadir menyertai tuturan itu. Benar disampaikan dalam banyak referensi buku pragmatik bahwa tuturan dalam perspektif 
pragmatik untuk mengetahui dan mengkaji maksud itu tidak dapat lepas dari konteksnya (Xu, Kemeny, Park, Frattali, \& Braun, 2005). Tuturan itu selalu terikat dengan konteksnya, tidak boleh dilepaskan atau ditelanjangi konteksnya. Jika demikian yang terjadi, keambiguankeambiguan dalam praktik berbahasa akan terus terjadi. Kesalahpahaman dan kesalahtafsiran juga akan menyertai keambiguan dalam memaknai maksud tuturan itu. Cuplikan tuturan berikut dapat diperhatikan lebih lanjut untuk lebih memahami hal ini.

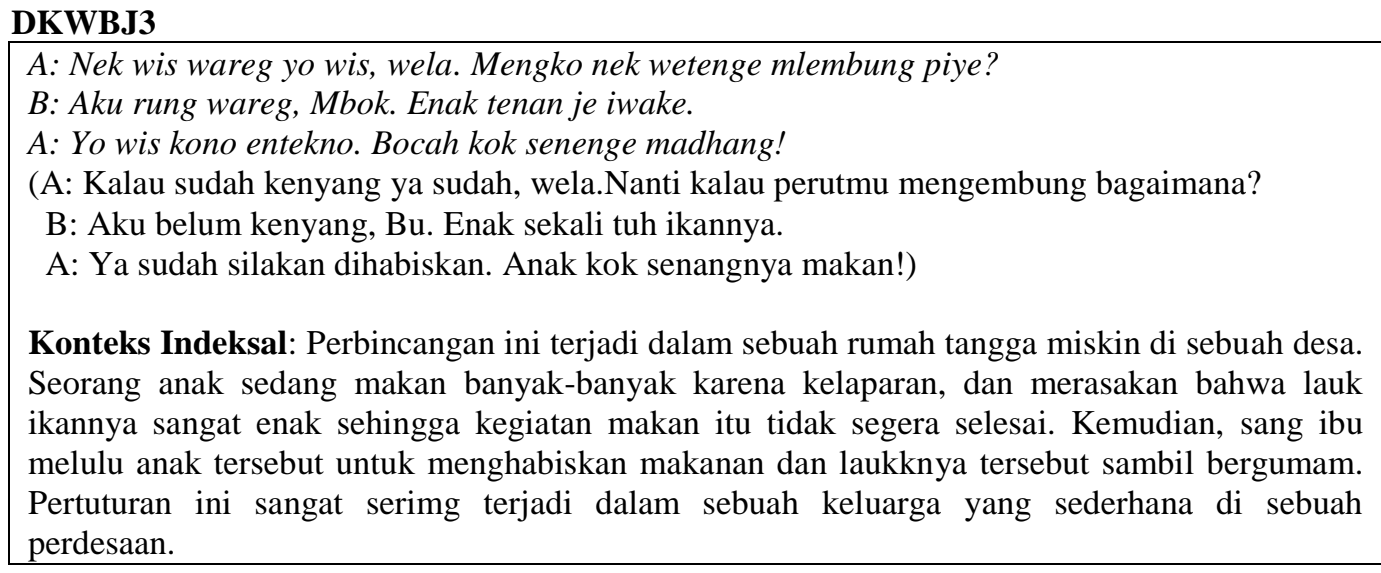

\section{Kata Emotif “Wela” untuk Menunjukkan Maksud Keheranan}

Keheranan tidak sama dengan keterkejutan. Orang yang merasa heran akan sesuatu yang sedang terjadi, tidak selalu harus merasa terkejut dengan sesuatu yang sedang dilihatnya tersebut. Jadi keheranan atau kekaguman itu tidak sama dengan keterkejutan, seperti yang telah dipaparkan di bagian terdahulu. Dalam DKWBJ4 berikut ini, "Wela, kojur tenan iki! Teles kabeh iki kasure, Mbok”. Sang kakak benar-benar spontan terheran-heran mendapati bahwa kasur tempat tidur adiknya yang masih kecil itu basah karena sang adik mengompol sewaktu tidur.

Tentu saja hal itu biasa dilakukan oleh anak-anak kecil yang belum dapat mengontrol dirinya sehingga ketika tidur dia buang air kecil di tempat tidur. Akan tetapi, keheranan itu tidak diteruskan dengan kemarahan, bahkan dia sebagai kakak dapat mengontrol diri dan memperingatkan ibunya yang cenderung lebih emosional dan terkesan akan memarahi anak kecil tersebut. Jadi jelas bahwa maksud keheranan muncul pada cuplikan tuturan berikut ini. Pembaca dipersilakan untuk mencermati tuturan lengkapnya agar dapat menafsirkan maksud dengan lebih akurat.

\section{DKWBJ4}

A: Wela, kojur tenan iki! Teles kabeh iki kasure, Mbok.

B: Lha piye to, Le. Ngompol ya adimu? Wah jan, bocah ra nggenah tenan kok.

A: Yo ben to, Mbok. Wong cah cilik ngompol kok dinesoni.

(A: Wela, celaka bener ini! Basah semua ini kasurnya, Bu.

B: Lha piye to, Nak. Ngompol ya adikmu? Wah sialan, anak ndak tahu diri bener kok. 
A: Ya sudah biar to, bu. Orang anak kecil ngompol kok dimarahi.)

Konteks Indeksal: Perbincangan ini terjadi antara seorang ibu dengan anaknya yang sudah cukup besar. Anak tersebut memiliki adik yang masih kecil dan biasa tidur sambil mengompol di tempat tidur. Sang ibu marah, tetapi diturunkan emosi tingginya oleh sang anak yang sudah relatuf lebih besar itu. Pertuturan yang terkasan tidak bernuansa harmonis dan cenderung kasar demikian ini banyak terjadi di desa-desa. Latar belakang pendidikan orang tua biasanya menjadi salah satu penentu dari hadirnya pertuturan yang tidak bagus demikian ini.

\section{Kata Emotif “Wela” untuk Menunjukkan Maksud Kelegaan untuk Bersyukur}

Ungkapan syukur atas peristiwa yang terjadi pada diri seseorang sangat baik dilakukan oleh setiap orang, terlebih-lebih kalau dia merasa mendapatkan anugerah dalam hidupnya. Para petani di perdesaan yang menjadi tempat penelitian ini pun demikian. Mereka merasa bersyukur dengan hadirnya gerimis sebagai petanda akan turunnya hujan di awal-awal musim penghujan. Rasa kelegaan yang menuntun petani itu untuk bersyukur tampak dengan jelas pada data DKWBJ5 berikut ini, khususnya yang berbunyi, "Wela, sokur tenan wis wiwit grimis. Bakal bisa labuh iki." Jadi berbeda sekali dengan contoh-contoh tuturan yang telah disampaikan sebelumnya, maksud "wela" pada cuplikan tuturan di atas adalah untuk menyampaikan kelegaan. Sang petani merasa lega karena akhirmya hujan yang dinantinantikan datang juga sekalipun masih dalam bentuk gerimis.

Pemerantian bahasa atau aspek-aspek kebahasan untuk mengungkapkan rasa syukur demikian ini sangat gayut dengan hakikat dari fungsi bahasa itu sendiri yang adalah untuk menjalin kerja sama dengan sesamanya (Rahardi, 2020). Dalam hal ini, yang dimaksud dengan sesama dalam berbahasa itu adalah Tuhan sendiri. Kedekatan hubungan yang demikian ini sangat penting dilakukan oleh setiap manusia, dan ternyata bahasa dapat mengemban peran untuk tercapainya maksud ini. Para pembaca dipersilakan mencermati cuplikan tuturan berikut untuk memahami lebih lanjut maksud kata emotif "wela” untuk menyampaikan maksud kelegaan dan syukur ini.

\section{DKWBJ5}

A: Wela, sokur tenan wis wiwit grimis. Bakal bisa labuh iki.

B: Iyo yo Kang. Nggolek banyu kok angele ra jamak.

A: Lha yo mongso ketiga yo ngene iki. Nek kesongo yo.

(A: Wela, syukur sekali sudah mulaio hujan gerimis. Bakal bisa menggarap sawah ini.

B: Iya ya, Mas. Mencari air kok sulit sekali.

A: Lha ya musim kemarau ya begini ini. Kalau musim hujan (kesembilan) ya.)

Konteks Indeksal: Pertuturan ini terjadi antarpetani di persawahan. Musim hujan yan tidak segera datang sangat menyusahkan para petani karena tidak dapat mengolah sawahnya dengan baik. Pada saat itu, gerimis mulai turun dan bersyukurlah para petani karena segera akan bisa bercocok tanam kembali. Irigasi yang tidak lancar, bahkan mati tentu saja sangat menyulitkan petani. 


\section{Kata Emotif “Wela” untuk Menunjukkan Maksud Kekecewaan}

Di dalam DKWBJ6 berikut ini, khususnya yang berbunyi, "Wela piye iki. Wis kebanjur ditanduri je malah ra udan-udan. Yo ra urip tandure" bentuk "wela" itu dimaksudkan untuk menyampaikan tujuan emotif kekecewaan. Dalam konteks ini kekeceewaan itu muncul karena ibu-ibu petani sudah telanjut tandur 'menanam padi'. Akan tetapi, setelah aktivitas menanam padi itu selesai, hujan tidak juga kunjung turun sehingga tanah persawahan itu kembali menjadi lahan kering. Keadaan yang demikian ini sangat sering dialami oleh para petani tradisional di perdesaan. Mereka sangat kesulitan dalam bercocok tanam di musim-musim kemarau terutama untuk lahan-lahan yang tidak dapat dijangkau oleh irigasi.

Mereka menyebutnya sebagai lahan sawah tadhah udan 'tadah hujan', yang tentu saja dapat digarap sebagai lahan pertanian bilamana hujan sudah turun. Jadi jelas sekali bahwa "wela" dalam cuplikan tuturan berikut ini digunakan untuk memgungkapkan maksud kekecewaan. Pembaca dipersilakan untuk mencermati lebih lanjut cuplikan ini agar dapat memahami maksud kata emotif "wela" dengan lebih baik. Jadi semakin terbukti bahwa bahasa bukan semata-mata berfungsi sebagai alat komunikasi. Bahasa juga dapat digunakan untuk menyatakan emosi (Tagliamonte, 2008). Dengan perkataan lain, fungsi emotif diemban oleh bentuk kebahasaan seperti "wela” dalam bahasa Jawa.

\begin{tabular}{l} 
DKWBJ6 \\
\begin{tabular}{|l|}
\hline A: Wela, piye iki. Wis kebanjur ditanduri je malah ra udan-udan. Yo ra urip tandure. \\
B: Iya yo. Ning yo sapa ngerti ndang udan maneh. Sesuk rak terus ledung-ledung godhonge! \\
A: Lha nek ora udan-udan ya nglowos. Wong tani jan ra iso apa-apa tenan. \\
(A: Wela bagaimana ini. Sudah teranjur ditanami malah tidak hujan-hujan. Ya tidak \\
hidup tanamannya. \\
B: Iya ya. Tapi ya siapa tahu segera hujan lagi. Besuk kan terus hijau-hijau subur \\
daunnya!) \\
Konteks Indeksal: Pertuturan ini terjadi antarpara ibu di desa-desa yang biasanya bekerja sama \\
menanam benih padi setelah sawah selesai digarap oleh para bapak petani. Pada saat itu mereka \\
mengeluhkan hujan yang tidak segera kunjung tutur. Dengan begitu, tanaman padi yang sudah \\
ditanamkannya tidak akan bisa tumbuh dan akhirnya tidak akan memiliki panenan untuk \\
meghidupi keluarga tersebut.
\end{tabular} \\
\hline
\end{tabular}

\section{PENUTUP}

Penelitian ini telah menemukan enam maksud kata emotif "wela" ditinjau dari perspektif sosiopragmatik. Keenam maksud itu disampaikan sebagai berikut: (1) menunjukkan maksud keterkejutan, (2) menunjukkan maksud pembelaan, (3) menunjukkan maksud mengingatkan, (4) menunjukkan maksud keheranan, (5) menenunjukkan maksud kelegaan untuk bersyukur, dan (6) menunjukkan maksud kekecewaan. Data yang lebih ekstensif dimungkinkan akan mampu menggambarkan maksud yang lebih ekstensif pula. 
Diakui penelitian ini memiliki keterbatasan, yakni dalam hal keluasan datanya. Dalam penelitian yang lebih besar, penulis akan memperluas data itu pada kesempatan lain. Para peneliti yang memilih perhatian sejenis juga dimungkinkan untuk meneliti hal serupa agar ke depan penelitian tentang kata emotif akan menjadi lebih lengkap.

\section{DAFTAR PUSTAKA}

Caffi, C., \& Janney, R. W. (1994). Toward a pragmatics of emotive communication. Journal of Pragmatics. https://doi.org/10.1016/0378-2166(94)90115-5

$\mathrm{Fu}$, M. (2004). On Sociopragmatic Equivalence Effect in Translation. US-China Foreign Language.

Helmon, S., \& Rahardi, R. K. (2020). Local values preservation of torok oral tradition through education domain: metaphorical ecolinguistics (preservasi nilai kearifan lokal tradisi lisan torok melalui ranah pendidikan: ekolinguistik metaforis). Gramatika STKIP PGRI Sumatera Barat. https://doi.org/10.22202/jg.2020.v6i1.3941

Holmes, J., \& King, B. W. (2017). Gender and sociopragmatics. In The Routledge Handbook of Pragmatics. https://doi.org/10.4324/9781315668925

Holmes, J., \& Marra, M. (2002). Having a laugh at work: How humour contributes to workplace culture. Journal of Pragmatics. https://doi.org/10.1016/S0378-2166(02)00032-2

Kunjana Rahardi, R. (2020). Building critical awareness of corona virus-related news: Cyberpragmatic study of COVID-19 hoaxes on social media. International Journal of Advanced Science and Technology.

Leech, G. (2014). The Pragmatics of Politeness. The Pragmatics of Politeness. https://doi.org/10.1093/acprof:oso/9780195341386.001.0001

Mahsun, M. (2005). Metode Penelitian Bahasa. Jakarta: PT Raja Grafindo Persada. https://doi.org/10.1200/JCO.2008.17.1991

Norrick, N. R. (2009). Interjections as pragmatic markers. Journal of Pragmatics. https://doi.org/10.1016/j.pragma.2008.08.005

Orsini-Jones, M., \& Lee, F. (2018). Intercultural communicative competence for global citizenship: Identifying cyberpragmatic rules of engagement in telecollaboration. Intercultural Communicative Competence for Global Citizenship: Identifying cyberpragmatic rules of engagement in telecollaboration. https://doi.org/10.1057/978-1-137-58103-7

Peace, A., \& Mühlhäusler, P. (2006). Environmental Discourses. Annual Review of Anthropology. https://doi.org/10.1146/annurev.anthro.35.081705.123203

Rahardi, R. Kunjana., Setyaningsih, Y. (2019). Contextualizing Local Values of Children's Games in the Perspective of Ecopragmatics to Enhance Culture-Specific Based Communication. International Journal of Engineering and Advanced Technology (IJEAT), 9(Issue-1, October 2019), 143-151. https://doi.org/10.35940/ijeat.A1096.109119

Rahardi, K. (2016). Personal and Communal Assumptions to Determine Pragmatic Meanings of Phatic Functions. Lingua Cultura, 10(2), 95. https://doi.org/10.21512/lc.v10i2.897

Rahardi, R. K. (2009a). Bahasa Indonesia untuk Perguruan Tinggi (1st ed.). Jakarta: Erlangga.

Rahardi, R. K. (2009b). Pragmatik: Kesantunan imperatif bahasa Indonesia. Jakarta: Erlangga.

Rahardi, R. K. (2010). Sosiopragmatik (1 st ed.). Jakarta: Erlangga.

Rahardi, R. K. (2019). Integrating social, societal, cultural, and situational contexts to develop pragmatics course learning materials. Studi, 5(2), 169-178. https://doi.org/10.22202/jg.2019.v5i2.3572

Sudaryanto. (2015). Metode dan Aneka Teknik Analisis Bahasa: Pengantar Penelitian Wahana Kebudayaan secara Linguistis (1st ed.). Yogyakarta: Sanata Dharma University Press.

Sudaryanto. (2016). Metode dan Aneka Teknik Analisis Bahasa (1st ed.). Yogyakarta: Sanata Dharma University Press.

Tagliamonte, S. (2008). Comparative Sociolinguistics. In The Handbook of Language Variation and Change. https://doi.org/10.1002/9780470756591.ch28

van Compernolle, R. A., \& Williams, L. (2012). Variationist sociolinguistics, L2 sociopragmatic 
competence, and corpus analysis of classroom-based synchronous computer-mediated discourse. In pragmatic variation in first and second language contexts: methodological issues. https://doi.org/10.1075/impact.31.09van

Xu, J., Kemeny, S., Park, G., Frattali, C., \& Braun, A. (2005). Language in context: emergent features of word, sentence, and narrative comprehension. NeuroImage. https://doi.org/10.1016/j.neuroimage.2004.12.013 